\title{
The Immunological Enigma of Human Giardiasis
}

\author{
Christian Klotz $^{1}$ - Toni Aebischer ${ }^{1}$
}

Published online: 5 July 2015

(C) Springer International Publishing AG 2015

\begin{abstract}
Giardiasis is a major cause of enteritis in humans worldwide. The disease is caused by two very distinct genetic groups (referred to as assemblages A and B) of the species complex Giardia duodenalis. The trophozoites stage colonizes the duodenum and jejunum of the small intestine and may cause a broad variety of disease outcomes that reach from asymptomatic carriers to patients with acute or chronic severe gastrointestinal complaints. Studies in immunocompromised patients imply that antibody-mediated acquired immune responses and a minimal $\mathrm{T}$ cell availability are of major importance for parasite clearance. These mechanisms likely play in concert with natural resistance mechanisms that are present in the intestinal mucosa. In humans no sterile immunity is acquired after infection. Epidemiological studies further suggest passive protection from symptomatic giardiasis in breastfed children. However, there is a fundamental lack of knowledge about the underlying immunological mechanisms of human giardiasis.
\end{abstract}

Keywords Giardia duodenalis $\cdot$ Human giardiasis $\cdot$ Immune response

This article is part of the Topical Collection on Protozoa (Giardia)

Christian Klotz

klotzc@rki.de

Toni Aebischer

aebischerA@rki.de

1 Division 16 Mycotic and parasitic agents and mycobacteria, Department of Infectious Diseases, Robert Koch-Institut, Nordufer 20, 13353 Berlin, Germany

\section{Introduction}

The purpose of the present review is to recapitulate what the outcome of Giardia infection in immunodeficient patients teaches us and to review recent advances in our knowledge of immunology of human giardiasis. This knowledge is compared to the evolving concepts in immunology with the eventual aim to identify current research gaps that need attention. For the interested readers, we also would like to refer to more detailed reviews on immunology and pathophysiology of giardiasis by others $[1 \cdot, 2-4,5 \cdot, 6]$.

Our knowledge about the immunological and pathophysiological mechanisms triggered during human infections with Giardia duodenalis (syn., G. intestinalis, G. lamblia) remains fragmented. The causative agents of giardiasis are the trophozoites that establish the infection in the duodenum and jejunum after excystation from the infectious dauer form, the cysts. Trophozoites are able to strongly attach to the luminal side of the epithelial cell layer with a highly specialized adhesive disc. Trophozoites possess eight flagella that enable motility. The parasites multiply by simple binary fission and reside exclusively extracellularly in the gut lumen. Their surface is dominated by variant surface protein. When reaching the lower small intestine, trophozoites transform (encystation) again into the infectious cyst stage that is shed with feces. A new infection is established by ingestion of infectious cysts, e.g., with contaminated food or water or by direct transmission from host to host $[1 \bullet]$.

We know that manifestation of $G$. duodenalis infections is highly variable. While many of the infected people remain asymptomatic, others show clinical symptoms that are rather unspecific and include serious diarrhea, abdominal pain and cramps, bloating, nausea, and vomiting. In chronically infected patients, symptomatic outcome is correlated with altered intestinal transport and barrier dysfunction [7]. Symptoms start 
usually after a prepatency period of about 7-10 days. Acute symptomatic infections mostly resolve spontaneously after 2 3 weeks. Recovery seems not to lead to immunity to reinfection. Moreover, chronic infection and treatment refractory courses of infection are common [8,9]. Postinfection sequelae, such as irritable bowel syndrome, chronic fatigue, and reactive arthritis $[10,9,11]$, have been described to occur after Giardia infections, but reasons and mechanisms remain obscure.

We also know that the variability in manifestation of giardiasis is matched by an even greater diversity in the etiologic agent. G. duodenalis is considered a species complex that consists of eight morphological identical but genetically distinct groups, designated as assemblages A-H. Assemblages A and $\mathrm{B}$ are pathogenic for humans and a wide range of animals and therefore are potentially zoonotic. Due to high sequence diversity, assemblage A and B are predicted to share only $78 \%$ amino acid sequence homology in proteins based on current genome examples, assemblages may have to be considered as two distinct species [12]. Both assemblage A and B parasite populations show significant sequence polymorphisms within themselves, a fact that is commonly used to further sub-divide the species complex. There is evidence from epidemiological studies that clinical manifestations may be related to infections with one or the other assemblage. However, studies yielded conflicting results which may be due to the rather low resolution of current typing methods and/or differences in the patient strata investigated.

\section{Giardiasis in Immunocompromised Humans}

Increased occurrence in patients with acquired or congenital immunodeficiencies have been very informative in other infections to reveal the most critical components of immunity. G. duodenalis infections are not particularly rare and we would like to reason that its prevalence of $1-4 \%$ even in high resource countries with very well-developed medical systems is high enough to reveal links to immune disorders if they existed. In the recent past, the AIDS epidemic revealed a number of such links. For example, Cryptosporidium spp have been clearly associated with severe enteritis in individuals with reduced $\mathrm{CD} 4^{+} \mathrm{T}$ cell counts [13]. However, symptoms and incidence of $G$. duodenalis infection in HIV/AIDS patients was not significantly altered. This suggests no direct role of CD4-T cells during giardiasis [14-17]. Although HIV/ AIDS patients have a lower anti-Giardia Ig response, they are still able to clear infection efficiently [18]. Other patients with cellular immunodeficiencies such as people affected by the DiGeorge syndrome or with severe combined immunodeficiency are also not more prone to symptomatic giardiasis $[19,20]$. Only when CD4 counts in HIV/AIDS patients become reduced to $\sim 1 \%$ of normal values was an increased risk of symptomatic $G$. duodenalis infections noted, indicating that only a minimal $\mathrm{T}$ cell compartment is necessary to support the control of Giardia infection in humans [21, 22, 13].

In contrast to $\mathrm{T}$ cell deficient patients, individuals with immune deficiencies that mainly affect B cells such as Xlinked agammaglobulinemia are more prone to chronic Giardia infection [23, 24, 20, 25]. A similar mutation in the mouse also leads to an elevated duration of Giardia muris primary infection $[26,27]$. In $\mu \mathrm{MT}$ mice that lack B cells, infections with $G$. duodenalis and G. muris have a contradictory outcome. While these mice controlled G. duodenalis infection, G. muris infection was prolonged [28, 29]. The latter discrepancy between G. muris and G. duodenalis infection in mice exemplarily highlights the difficulties to use mice infected with $G$. duodenalis as a model for human giardiasis.

From this recapitulation, it follows that symptomatic G. duodenalis infections are correlated with and possibly controlled by antibody enhanced effector mechanisms. However, there is also evidence for antibody-independent control mechanisms.

\section{Natural Resistance Mechanisms}

Mucosal Fluids Although the parasites colonize the duodenum and jejunum, earlier studies have shown that Giardia trophozoites can be killed in vitro by incubation with duodenal fluid from non-infected individuals due to free fatty acids or other products of lipolysis [30]. The toxic effects of these products can be reverted in vitro by addition of bovine serum albumin or human duodenal-jejunal mucus most likely due to trapping of the toxic compounds [30]. Epidemiological studies reveal a correlation between protection from symptomatic giardiasis in newborn children with breastfeeding, and this has been attributed to the occurrence of $G$. duodenalis-specific antibodies (mainly sIgA) in the milk of the mothers [31-34]. But, milk from non-infected mothers was also shown to kill parasites in vitro which was linked to toxic products of lipolysis too $[35,36]$. The relative contribution of these toxic products to protection due to breastfeeding is not entirely clear, but they likely act in concert with anti-G. duodenalis secretory immunoglobulin A (sIgA). Lactoferrin is another antimicrobial component of the human milk that may interfere with $G$. duodenalis infections in children [37]. Human milk is complex, and in addition to fatty acids, lactoferrin and SIgA, they comprise a multitude of anti-microbial substances. Lysozyme, lactoperoxidases, kappa-casein, haptocorrin, alpha-lactalbumin, complex oligosaccharides, and mucins, and even cytokines and cells of the immune system such as macrophages, granulocytes, and other leucocytes, are present [38-40]. It requires much more research to define to which extend the various components contribute to protection of the newborn from symptomatic giardiasis. It is also an open question how the developing gut of neonates responds to 
G. duodenalis infections and how breastfeeding impacts on this system [40].

Mucins G. duodenalis trophozoites require motility for colonization as they need to translocate through the mucus layer in order to adhere to epithelial cells [41, 42]. Apart from motility, little is known how trophozoites are able to pass this layer and how they survive the anti-microbial defense mechanisms associated with the mucin layer in the small intestine. The latter include $\alpha$-defensins, cathelicidins, lysozymes, angiogenin 4 , secreted phospholipase A2, lectins, and collectins [41]. A recent study shows lectin-binding dependent killing of Giardia trophozoites by complement, but the role of lectin-binding in the intestinal lumen is unclear [43]. The mucin Muc 2, mainly produced by Goblet cells, is the major gel-forming component of the mucus layer in the small intestine, and it has been suggested that excretory/secretory products of the parasite, likely cysteine proteases and glycosidases, degrade the mucus [44, 45, 42]. On the one hand, mucus may stimulate growth and protect trophozoites from toxic effects of human milk [46-48]; on the other hand, mucus was also shown to inhibit trophozoite attachment to culture dishes [49]. Mechanisms underlying these divergent effects are not understood. As mucus composition and role as anti-parasitic effector can change during infection as recently shown for gastrointestinal nematode infections [50], its role needs to be further investigated in giardiasis.

Intestinal Proteases Intestinal proteases are also able to induce G. duodenalis' death in vitro, which is partly dependent on the type of variant surface protein expressed on the surface of the trophozoites [51]. The surface of the parasite is dominated by a single member of this vast family of proteins to which it devotes a significant portion of its coding genome. While most of the trophozoites will be dying after treatment with intestinal proteases, some parasites survive presumably because they express a protease resistant variable surface protein (VSP) member on their surface. Biochemical analysis indicated that certain VSPs are resistant to proteolytic cleavage [51, 52]. Studies in SCID mice that lack an adaptive immune system show selective growth of mouse-adapted $G$. duodenalis clones with specific VSPs. This indicates that VSP-dependent selection can occur independently from anti-VSP immunoglobulins [53, 54]. VSP switching is thus thought of as an escape mechanism, but it should be highlighted that assemblages can show very different VSP switching behaviors, e.g., G. duodenalis strain WB6 (assemblage AI) switches approximately every 12 generations while strain GS (assemblage B) approximately every 6 generations [55]. This difference may greatly influence a parasite's ability to establish infection and evade control.
Defensins These anti-microbial peptides are mainly produced by epithelial cells and neutrophils. In the gut, high concentrations of specific $\alpha$-defensins are found in the crypts of the intestinal layer, where they are produced by Paneth cells. In vitro, data suggested that $G$. duodenalis trophozoites are selectively susceptible to different human and mouse defensins [56]. The real impact of intestinal defensins on G. duodenalis infection is unclear and understudied, but data from mouse models suggest that they play a role in protection $[3,57 \bullet]$.

Nitric Oxide Inducible nitric oxide (iNOS) is an important effector molecule against many pathogens and is for example produced by proinflammatory macrophages. In mice iNOS (NOS2), depletion alone showed no alteration in parasite load [58]. In vitro studies however confirmed profound giardiastatic effect of NO [59]. Beside iNOS, two other enzyme isoforms in neurons (NOS1) and endothelial cells (NOS3) exist that produce NO as a neurotransmitter. In enteric neurons, NO is involved in the modulation of enteric muscle contraction and bowel movement. It has been shown that NO is one mediator for increased intestinal propulsion that eliminates $G$. duodenalis infection in mice [60,58]. Studies suggest that NO plays in concert with another neurotransmitter, cholecystokinin (CCK), to increase intestinal compulsion and thus intestinal transit rates $[60,5 \cdot]$. To date, the validation of findings in murine models with respect to iNOS has met great difficulties in attempts to translate this to the human situation due to the very different nature of triggers of iNOS expression in human cells. Thus, a role for iNOS or, more generally, NO in humans with giardiasis remains speculative.

All these data imply that $G$. duodenalis infections are controlled to a variable degree by natural resistance mechanisms that may play in concert with innate and adaptive immune factors. However, in humans, this subject is greatly understudied, and the role of these natural resistance mechanisms as a selective force during colonization with various assemblages (species) or sub-assemblages of the parasite is not clear and greatly understudied. Their effect on isolates of different genetic composition should be advocated as a focus of future investigations. To date, most studies have been performed using either one of the laboratory strains WB (assemblage A) or GS (Assemblage B), but we lack a systematic analysis of a broader variety of isolates.

\section{Innate Immunity}

The key immunological concept governing the initiation of an immune response is the recognition of foreign entities by cells using pattern recognition receptors (PRR) located at external or internal membranes or in the cytoplasm [61]. Many of these receptors are expressed not only by cells of the immune 
system but also by mucosal epithelial cells. Arguably, two main cell types first come into contact with $G$. duodenalis trophozoites and may thus mediate the underlying innate and adaptive immune responses; epithelial cells such as enterocytes, Goblet cells, and Paneth cells that derive from the intestinal stem cell lineage lining the intestinal layer and mucosal innate immune cells including intestinal macrophages, intestinal and plasmacytoid dendritic cells (DCs), eosinophils, mast cells, invariant natural killer T cells (iNKT), mucosal-associated invariant T cells (MAIT), and the recently identified innate lymphoid cells (ILC1, ILC2, ILC3) [62]. In giardiasis, responses of only two of these cell types have been analyzed in some detail: enterocytes and mononuclear phagocytic cells (mainly blood monocyte-derived DCs).

Enterocytes Gene expression analysis of human intestinal epithelial cells, Caco-2 cells, co-cultured with G. duodenalis (WB6) trophozoites, revealed a very early increase of various chemokines and chemokine receptors including CCL20, CCL2, and CXCR4 [63]. Upregulation of several transcription factors imply a complex stimulation cascade in enterocytes upon contact with trophozoites that also involve Nf-kB and mitogen-activated phospho-kinases (MAPK) signaling $[63,64]$. This response would be consistent with recognition of the pathogen by a PRR, but the respective receptors have not been identified. However, the response is also compatible with the reaction of epithelial cells to nutritional stress as sensed by the mTOR pathway and linking to an ER stress response pattern [65]. In mice, ER stress response engineered to occur in the mucosal epithelial cells induces inflammation [66].

The release of chemoattractants such as CCL20 by enterocytes has not been further studied, but they may lead to recruitment of cells of the immune system to the gut. Histologically, this would be recorded as inflammation. However, the occurrence of local inflammation in the G. duodenalis-infected tissue has been controversial. Data of some studies are interpreted as evidence that inflammation is only rarely associated with giardiasis in humans $[67,68,5 \cdot]$. The largest study analyzed intestinal biopsies of approximately 19,000 patients, consecutive cases with "unspecific gastrointestinal complaints." In 567 of these specimens, G. duodenalis trophozoites were identified, but no significant increase in cell infiltration compared to control specimens was observed [67]. However, this study design did not allow to investigate asymptomatic versus symptomatic cases of G. duodenalis infection. In fact, the frequency of infections observed was $0.3 \%$ which is even below the expected prevalence of infection of cross sectional studies. We suggest that this large data set reflects sampling of asymptomatic infections. In contrast, when the study design was focused on chronically infected symptomatic giardiasis patients, a significant increase in CD3-positive intraepithelial lymphocytes
(IEL) in the infected tissues was found and was accompanied by epithelial barrier dysfunction [7]. Moreover, clinically manifested disease has been positively correlated to parasite density.

Mononuclear Phagocytic Cells Both mononuclear phagocytic cell types in the gut, intestinal macrophages, and DCs are considered to play a major role for antigen uptake and presentation. In comparison to other macrophage populations in the body, intestinal macrophages express high levels of MHC class II on the surface and there are difficulties to differentiate functionally intestinal macrophages and DC in the gut [62]. There are no G. duodenalis studies available on intestinal mononuclear phagocytic cells from humans. To study the response of DC upon stimulation with G. duodenalis products, monocyte-derived DCs (MoDC) have been generated from human blood. In congruence with the lack of inflammation in the gut, G. duodenalis trophozoites or trophozoites products activate cytokine/chemokine response or maturation of human (and mouse) dendritic cells only weakly if at all $[69,70]$. However, $G$. duodenalis extracts alter the response of human MoDCs co-stimulated with known PRR-ligands such as some recognized by Toll like receptors (TLRs). TLR4 (lipopolysaccharide (LPS))-stimulated MoDCs in the presence of $G$. duodenalis extracts secreted lower levels of IL-12 and IL-23 and higher levels of IL-10 and reduced surface expression of CD25, CD83, CD86, and HLADR, while TLR2 ligand (Pam)-stimulated MoDCs increased all cytokine levels (IL-12, IL-23, IL-10) and surface markers indicating a modulatory effect on stimulated DCs [70]. A recent study in mice identified intestinal macrophages expressing arginase 1 and nitric oxide synthase 2 in the small intestine during G. duodenalis infection [71]. Arginase 1 is one marker of alternatively activated macrophages typically found in a Th2 environment. Whether or not alternatively activated macrophages occur during human giardiasis is unknown.

It should be noted that intestinal mononuclear phagocytic cells are central for antigen presentation to $\mathrm{T}$ - and $\mathrm{B}$ cells, but it is believed that they respond in concert with a variety of other possible responsive cells such as basophils, mast cells, iNKT, MAIT, innate lymphoid cells (ILCs), stromal cells, and epithelial cells $[72,73,62]$. It is unknown which role these cells play during human giardiasis, and it would be necessary to study the cell-cell network between all these cell types in the human context. It would be of particular interest how G. duodenalis infections affect the newly identified ILCs [74] and how these cells may contribute to the immune reaction to giardiasis in humans.

Data, from murine models, suggest a role for mast cells. Mast cell deficient mice (c-kit $\left.{ }^{w / w v}\right)$ are not able to eliminate the $G$. duodenalis infection likely due to a subsequently diminished IgA response and/or reduced bowel movement [75, 60]. Besides DC, mast cells may be important for IL-6 
production, which has been shown to be an important factor for parasite clearance in the mouse [76-78].

Taken together, the reaction and role during human giardiasis of mucosal innate immune cells is almost completely unknown. However, based on the currently available data, we would like to suggest that $G$. duodenalis is not registered by the immune system for want of ligands of PRRs. Instead, sensing the infection requires high parasite densities able to cause nutritional stress which provides the required signal to the host cells. Keeping colonization density below a not yet known threshold by natural resistance mechanisms as discussed above will enable $G$. duodenalis to remain below the limit of the immune systems' surveillance capacity. Once crossing the threshold, an inflammatory reaction triggered initially by nutritional stress could cause inflammation and symptomatic disease but also adaptive immunity which together with IgA may eventually amplify the effectiveness of the natural resistance mechanisms to control pathogen densities.

\section{Adaptive Immune Responses}

Data from mice suggest that innate immune responses triggered by nutritional stress or ER stress appear not to instruct adaptive immune responses that are highly skewed to e.g., type 1 or type 2 responses [66]. In human giardiasis, the few studies available reveal that $G$. duodenalis infection does not induce a highly biased cytokine response during the course of infection, i.e., no clear $\mathrm{T}$ cell polarization is associated with human giardiasis. In two studies using the same samples, IL-5, IL-6, IL-13, TNF- $\alpha$, and INF- $\gamma$ levels were analyzed before and 2 and 8 weeks after treatment and an increase of all cytokines at all time points compared to healthy controls was found $[79,80]$. In the same studies, NO and IgE were analyzed and also revealed a higher serum level compared to the control sera. In another study, only a significant increase in IL2 was detectable but there was no significant increase of IL-4 or IL-10 in giardiasis patients [81, 82], but measuring the latter is notoriously difficult in human cells. A study in children showed only an increase in certain cytokines (IL-1, IL-6, IL8 ) or C-reactive protein (CRP) and NO when giardiasis was in addition associated with allergy [82]. A study in Venezuela analyzed IL-13, IFN- $\gamma$, IL 6, and IL-10 levels in G. duodenalis-infected children and found also only a moderate increase of all cytokines in the serum compared to uninfected controls. These levels were profoundly increased by Ascaris lumbricoides co-infection [83]. The same group also found that giardiasis may enhance the outcome of atopic dermatitis allergic reactions in school children [84]. But G. duodenalis infection was also found to reduce granulocyte infiltration in an in vivo model of bacterial toxin-induced colitis and attenuates inflammation in human intestinal tissue suggesting modulating immune responses during giardiasis [85].

Analysis of local responses by lamina propria lymphocytes from naïve human individuals revealed an increased proliferation and elevated IFN- $\gamma$ response after stimulation with Giardia antigen and has been interpreted as a "mitogenic" effect by the parasite [86]. A study on fecal cytokine excretion has found that elevated levels of MCP-1, IFN- $\gamma$, IL-4, and IL5 are associated with a longer $G$. duodenalis infection outcome. In contrast, elevated IL-8 levels were associated with shorter infection times in the studied child population [87]. A recent study analyzing the cellular proliferation of blood lymphocytes in patients who had suffered from giardiasis 5 years earlier ("Bergen outbreak") revealed a significant elevation of Giardia-specific proliferation indicating $\mathrm{T}$ cell memory. Activation markers were also analyzed but were inconclusive [88•].

Experimental G. duodenalis infections in humans and epidemiological studies reveal that no sterile immunity is mounted. Rather, protection against symptomatic infections is acquired through primary infections [89-91]. It is not known whether and if yes to what extent infection with one assemblage protects from symptomatic reinfection with another assemblage. Recent publications suggested G. duodenalis genotype specific differences in pathogenesis in animal models $[92 \cdot, 93,94]$. However, and as mentioned before, epidemiological studies in humans that try to link infection with different assemblages to clinical outcome are inconclusive [95-97, 31, 98, 99].

\section{Giardia Factors Known to Interact with the Immune System}

Only a few virulence factors and immune-reactive entities are described for $G$. duodenalis, most of which refer to structural features like the motility through flagella and the ventral adhesive disc (e.g., giardins/annexins) [1 0 . The highly antigenic VSP coat on the parasite surface is thought to enable immune evasion by antigen-switching to escape protective antibody responses and is thought to mediate protection to natural resistance mechanisms as described above [55]. However, how much this VSP surface repertoire is contributing to pathogenicity and virulence in humans is still understudied in particular with respect of the broad variety of genetic differences in human isolates. Besides this, only very few candidate virulence factors are described. Candidate proteins may be immunogenic and therefore recognized by $G$. duodenalis-specific serum antibodies. This idea has led to identification of a number of antigens, including heat shock proteins, tubulins and several other not further analyzed proteins [100-107]. A prominent candidate is the arginine deiminase (ADI) that has been identified as one of 16 immuno-dominant, non-variant 
G. duodenalis proteins (examples of additional antigens are $\alpha$-giardins, ornithine carbamoyl transferase, and fructose-1,6bisphosphate aldolase) in a screening assay with human sera from individuals with acute giardiasis [108]. As other metabolic enzymes, ADI is released by an unknown mechanism upon contact with epithelial cells. ADI-dependent hydrolysis of arginine has been linked to inhibited production of the immune effector $\mathrm{NO}$, to reduced proliferation of epithelial cells and of T lymphocytes [59, 109-111]. Arginine depletion by ADI also modulates the phenotype and cytokine release from LPS-activated MoDC which in part involves mTOR signaling, one of the sensing pathways of nutritional stress [112].

The mechanisms by which $G$. duodenalis trophozoites modulates the immune response of enterocytes and DCs and possibly other cell types remains unknown, and we strongly favor nutritional stress as one component of it. However, a recently identified " $G$. duodenalis binding immunoglobulin protein" suggests also a direct pathway to trigger - in this case-murine DC maturation via TLR4 and MAPK pathways, [113] but this awaits confirmation using human cells. A pattern recognition-independent stimulation of immune responses by G. duodenalis is reminiscent of Th2-type responses induced during helminth's infections, which also in many cases do not prime via PRRs [73]. Th2 responses have been associated with a broad variety of initiating mechanisms including protease activity, metabolic stresses induced by the pathogen or by pathogen tissue damage [73]. In this respect, it is noteworthy that $G$. duodenalis parasites secrete a broad variety of cysteine proteases $[85,45,114,115]$ that may also play a part in a PRR-independent immune response. Such proteins were shown to stimulate a mixed Th1/Th2-like in mice [116]. Cysteine proteases may also be involved in mediating apoptosis in enterocytes and immune evasion, e.g., by cleavage of IL-8 released from enterocytes [45, 115, 85]. Together with secretion of metabolic enzymes such as ADI that may deplete arginine locally which may result in a nutritional stress environment, cysteine proteases may influence the outcome of the immune response in particular in newborn humans as it has been shown for bacterial infections [117]. Studying the impact of these enzymes during human G. duodenalis infection deserves more attention and needs to be integrated with the elucidation of $G$. duodenalis assemblage specific differences in these factors that could explain genotype-clinical phenotype correlations [92•, 93, 99].

\section{Conclusion}

Functional studies on human giardiasis are scarce. Available data point towards a mixed type immune response with an antibody-driven component important to control G. duodenalis infections. It is unknown which
G. duodenalis factors shape the immune response and whether they are polymorphic between assemblages A and B and within these genotypic units. Our interpretation of current knowledge as presented above is certainly an oversimplification but is intended to identify major knowledge gaps (Box 1) and to provide a framework to formulate testable hypotheses.

Box 1: Important open research questions in immunology of human giardiasis.

Q1: What are the adaptive immune response dependent and independent protective components of human milk? Do they shape the parasite population present in breast fed infants?

Q2: What is the particular role of gut associated natural resistance mechanisms such as mucins, defensins and proteases also as selecting factors for the variety of $\mathrm{G}$. duodenalis assemblages and subassemblages infecting the human gut?

Q3: What is the response of the various stem cell derived epithelial cells, e.g., Paneth cells, goblet cells and primary enterocytes, in the small intestine to $\mathrm{G}$. duodenalis infection?

Q4: What is the mechanistic trigger of the response of mucosal innate immune cells such as intestinal macrophages, intestinal and plasmacytoid DCs, eosinophils, mast cells, invariant natural killer T cells (iNKT), mucosal-associated invariant T cells (MAIT), and the recently identified innate lymphoid cells (ILC1, ILC2, ILC3) in giardiasis? How do these cells communicate to each other and to other cell types in the gut like epithelial cells and lymphocytes?

Q5: What is the effector mechanism underlaying immunoglobulindependent control of Giardia infections in humans?

Q6: What are the main G. duodenalis virulence factors and are they functionally polymorphic in different assemblages or subassemblages?

\section{Compliance with Ethics Guidelines}

Conflict of Interest The authors declare that they have no competing interests.

Human and Animal Rights and Informed Consent This article does not contain any studies with human or animal subjects performed by any of the authors.

\section{References}

Papers of particular interest, published recently, have been highlighted as:

- Of importance

1. Ankarklev J, Jerlstrom-Hultqvist J, Ringqvist E, Troell K, Svard SG. Behind the smile: cell biology and disease mechanisms of Giardia species. Nat Rev Microbiol. 2010;8(6):413-22. An excellent review that provides current knowledge about cell biology and disease mechanism of Giardia infections.

2. Buret AG, Cotton JA. Pathophysiological processes and clinical manifestation of giardiasis. In: Luján HD, Svärd S, editors. Giardia a model organism. Wien: Springer; 2011. p. 301-18. 
3. Eckmann L. Mucosal defences against Giardia. Parasite Immunol. 2003;25(5):259-70.

4. Faubert G. Immune response to Giardia duodenalis. Clin Microbiol Rev. 2000;13(1):35-54.

5. Singer SM. Immunology of giardiasis. In: Luján HD, Svärd S, editors. Giardia: a model organism. Wien: Springer; 2011. p. 319-31. An excellent review that provides comprehensive summary of 'Immunology of Giardiasis'.

6. Solaymani-Mohammadi S, Singer SM. Giardia duodenalis: the double-edged sword of immune responses in giardiasis. Exp Parasitol. 2010;126(3):292-7.

7. Troeger H, Epple HJ, Schneider T, Wahnschaffe U, Ullrich R, Burchard GD, et al. Effect of chronic Giardia lamblia infection on epithelial transport and barrier function in human duodenum. Gut. 2007;56(3):328-35.

8. Escobedo AA, Hanevik K, Almirall P, Cimerman S, Alfonso M. Management of chronic Giardia infection. Expert Rev Anti-Infect Ther. 2014;12(9):1143-57.

9. Robertson LJ, Hanevik K, Escobedo AA, Morch K, Langeland N. Giardiasis - why do the symptoms sometimes never stop? Trends Parasitol. 2010;26(2):75-82.

10. Carlson DW, Finger DR. Beaver fever arthritis. J Clin Rheumatol Prac Rep Rheumatic Musculoskeletal Dis. 2004;10(2):86-8.

11. Wensaas KA, Langeland N, Hanevik K, Morch K, Eide GE, Rortveit G. Irritable bowel syndrome and chronic fatigue 3 years after acute giardiasis: historic cohort study. Gut. 2012;61(2):214 9.

12. Jerlstrom-Hultqvist J, Ankarklev J, Svard SG. Is human giardiasis caused by two different Giardia species? Gut Microbes. 2010;1(6): 379-82.

13. Stark D, Barratt JL, van Hal S, Marriott D, Harkness J, Ellis JT. Clinical significance of enteric protozoa in the immunosuppressed human population. Clin Microbiol Rev. 2009;22(4):634-50.

14. Barrett DM, Steel-Duncan J, Christie CD, Eldemire-Shearer D, Lindo JF. Absence of opportunistic parasitic infestations in children living with HIV/AIDS in children's homes in Jamaica: pilot investigations. The West Indian Med J. 2008;57(3):253-6.

15. Carcamo C, Hooton T, Wener MH, Weiss NS, Gilman R, Arevalo $\mathrm{J}$, et al. Etiologies and manifestations of persistent diarrhea in adults with HIV-1 infection: a case-control study in Lima, Peru. J Infec Dis. 2005;191(1):11-9.

16. Stark D, Fotedar R, van Hal S, Beebe N, Marriott D, Ellis JT, et al. Prevalence of enteric protozoa in human immunodeficiency virus (HIV)-positive and HIV-negative men who have sex with men from Sydney, Australia. AmJTrop Med Hyg. 2007;76(3):549-52.

17. Viriyavejakul P, Nintasen R, Punsawad C, Chaisri U, Punpoowong B, Riganti M. High prevalence of Microsporidium infection in HIV-infected patients. Southeast Asian J Trop Med Public Health. 2009;40(2):223-8.

18. Janoff EN, Smith PD, Blaser MJ. Acute antibody responses to Giardia lamblia are depressed in patients with AIDS. J Infect Dis. 1988;157(4): 798-804.

19. Roberts-Thomson IC. Genetic studies of human and murine giardiasis. Clin Infect Dis Off Pub Infec Dis Soc Am. 1993;16 Suppl 2:S98-104

20. Webster AD. Giardiasis and immunodeficiency diseases. Trans R Soc Trop Med Hyg. 1980;74(4):440-3.

21. Angarano G, Maggi P, Di Bari MA, Larocca AM, Congedo P, Di Bari C, et al. Giardiasis in HIV: a possible role in patients with severe immune deficiency. Eur J Epidemiol. 1997;13(4):485-7.

22. Dwivedi KK, Prasad G, Saini S, Mahajan S, Lal S, Baveja UK. Enteric opportunistic parasites among HIV infected individuals: associated risk factors and immune status. Jpn J Infect Dis. 2007;60(2-3):76-81.
23. Perlmutter DH, Leichtner AM, Goldman H, Winter HS. Chronic diarrhea associated with hypogammaglobulinemia and enteropathy in infants and children. Dig Dis Sci. 1985;30(12):1149-55.

24. Van der Hilst JC, Smits BW, van der Meer JW. Hypogammaglobulinaemia: cumulative experience in 49 patients in a tertiary care institution. Neth J Med. 2002;60(3):140-7.

25. Ament ME, Ochs HD, Davis SD. Structure and function of the gastrointestinal tract in primary immunodeficiency syndromes. A study of 39 patients. Medicine (Baltimore). 1973;52(3):227-48.

26. Snider DP, Gordon J, McDermott MR, Underdown BJ. Chronic Giardia muris infection in anti-IgM-treated mice. I. Analysis of immunoglobulin and parasite-specific antibody in normal and immunoglobulin-deficient animals. J Immunol. 1985;134(6): 4153-62.

27. Snider DP, Skea D, Underdown BJ. Chronic giardiasis in B-celldeficient mice expressing the xid gene. Infect Immun. 1988;56(11):2838-42.

28. Langford TD, Housley MP, Boes M, Chen J, Kagnoff MF, Gillin FD, et al. Central importance of immunoglobulin A in host defense against Giardia spp. Infect Immun. 2002;70(1):11-8.

29. Singer SM, Nash TE. T-cell-dependent control of acute Giardia lamblia infections in mice. Infect Immun. 2000;68(1):170-5.

30. Das S, Reiner DS, Zenian J, Hogan DL, Koss MA, Wang CS, et al. Killing of Giardia lamblia trophozoites by human intestinal fluid in vitro. Asian J Infect Dis. 1988;157(6):1257-60.

31. Ignatius R, Gahutu JB, Klotz C, Steininger C, Shyirambere C, Lyng M, et al. High prevalence of Giardia duodenalis assemblage $\mathrm{B}$ infection and association with underweight in Rwandan children. PLoS Negl Trop Dis. 2012;6(6), e1677.

32. Mahmud MA, Chappell CL, Hossain MM, Huang DB, Habib M, DuPont HL. Impact of breast-feeding on Giardia lamblia infections in Bilbeis, Egypt. AmJTrop Med Hyg. 2001;65(3):257-60.

33. Tellez A, Palm D, Weiland M, Aleman J, Winiecka-Krusnell J, Linder E, et al. Secretory antibodies against Giardia intestinalis in lactating Nicaraguan women. Parasite Immunol. 2005;27(5):1639.

34. Tellez A, Winiecka-Krusnell J, Paniagua M, Linder E. Antibodies in mother's milk protect children against giardiasis. Scand J Infect Dis. 2003;35(5):322-5.

35. Reiner DS, Wang CS, Gillin FD. Human milk kills Giardia lamblia by generating toxic lipolytic products. Asian J Infect Dis. 1986;154(5):825-32.

36. Rohrer L, Winterhalter KH, Eckert J, Kohler P. Killing of Giardia lamblia by human milk is mediated by unsaturated fatty acids. Antimicrob Agents Chemother. 1986;30(2):254-7.

37. Ochoa TJ, Chea-Woo E, Campos M, Pecho I, Prada A, McMahon $\mathrm{RJ}$, et al. Impact of lactoferrin supplementation on growth and prevalence of Giardia colonization in children. Clin Infect DisOff Pub Infect Dis Soc Am. 2008;46(12):1881-3.

38. Brandtzaeg P. Mucosal immunity: integration between mother and the breast-fed infant. Vaccine. 2003;21(24):3382-8.

39. Field CJ. The immunological components of human milk and their effect on immune development in infants. J Nutr. 2005;135(1):14.

40. Newburg DS, Walker WA. Protection of the neonate by the innate immune system of developing gut and of human milk. Pediatr Res. 2007;61(1):2-8.

41. McGuckin MA, Linden SK, Sutton P, Florin TH. Mucin dynamics and enteric pathogens. Nat Rev Microbiol. 2011;9(4):265-78.

42. Yoshida N, Tyler KM, Llewellyn MS. Invasion mechanisms among emerging food-borne protozoan parasites. Trends Parasitol. 2011;27(10):459-66.

43. Evans-Osses I, Ansa-Addo EA, Inal JM, Ramirez MI. Involvement of lectin pathway activation in the complement killing of Giardia intestinalis. Biochem Biophys Res Commun. 2010;395(3):382-6. 
44. Connaris S, Greenwell P. Glycosidases in mucin-dwelling protozoans. Glycoconj J. 1997;14(7):879-82.

45. de Carvalho TB, David EB, Coradi ST, Guimaraes S. Protease activity in extracellular products secreted in vitro by trophozoites of Giardia duodenalis. Parasitol Res. 2008;104(1):185-90.

46. Gault MJ, Gillin FD, Zenian AJ. Giardia lamblia: stimulation of growth by human intestinal mucus and epithelial cells in serumfree medium. Exp Parasitol. 1987;64(1):29-37.

47. Zenian A, Gillin FD. Interactions of Giardia lamblia with human intestinal mucus: enhancement of trophozoite attachment to glass. J Protozool. 1985;32(4):664-8.

48. Zenian AJ, Gillin FD. Intestinal mucus protects Giardia lamblia from killing by human milk. J Protozool. 1987;34(1):22-6.

49. Roskens H, Erlandsen SL. Inhibition of in vitro attachment of Giardia trophozoites by mucin. J Parasitol. 2002;88(5):869-73.

50. Hasnain SZ, Gallagher AL, Grencis RK, Thornton DJ. A new role for mucins in immunity: insights from gastrointestinal nematode infection. Int J Biochem Cell Biol. 2013;45(2):364-74.

51. Nash TE, Merritt Jr JW, Conrad JT. Isolate and epitope variability in susceptibility of Giardia lamblia to intestinal proteases. Infect Immun. 1991;59(4):1334-40.

52. Papanastasiou P, Bruderer T, Li Y, Bommeli C, Kohler P. Primary structure and biochemical properties of a variant-specific surface protein of Giardia. Mol Biochem Parasitol. 1997;86(1):13-27.

53. Adam RD, Nigam A, Seshadri V, Martens CA, Farneth GA, Morrison HG, et al. The Giardia lamblia vsp gene repertoire: characteristics, genomic organization, and evolution. BMC Genomics. 2010;11:424.

54. Singer SM, Elmendorf HG, Conrad JT, Nash TE. Biological selection of variant-specific surface proteins in Giardia lamblia. Asian J Infect Dis. 2001;183(1):119-24.

55. Nash TE. Antigenic variation in Giardia. In: Luján HD, Svärd S, editors. Giardia: a model organism. Wien: Springer; 2011. p. 245-57.

56. Aley SB, Zimmerman M, Hetsko M, Selsted ME, Gillin FD. Killing of Giardia lamblia by cryptdins and cationic neutrophil peptides. Infect Immun. 1994;62(12):5397-403.

57. Tako EA, Hassimi MF, Li E, Singer SM. Transcriptomic analysis of the host response to Giardia duodenalis infection reveals redundant mechanisms for parasite control. mBio. 2013;4(6). This is an excellent research paper that nicely shows that $G$. duodenalis infections may be controlled by redundant host response mechanisms.

58. Li E, Zhou P, Singer SM. Neuronal nitric oxide synthase is necessary for elimination of Giardia lamblia infections in mice. $\mathrm{J}$ Immunol. 2006;176(1):516-21.

59. Eckmann L, Laurent F, Langford TD, Hetsko ML, Smith JR, Kagnoff MF, et al. Nitric oxide production by human intestinal epithelial cells and competition for arginine as potential determinants of host defense against the lumen-dwelling pathogen Giardia lamblia. J Immunol. 2000;164(3):1478-87.

60. Li E, Zhao A, Shea-Donohue T, Singer SM. Mast cell-mediated changes in smooth muscle contractility during mouse giardiasis. Infect Immun. 2007;75(9):4514-8.

61. Kawai T, Akira S. The role of pattern-recognition receptors in innate immunity: update on Toll-like receptors. Nat Immunol. 2010;11(5):373-84.

62. Mowat AM, Agace WW. Regional specialization within the intestinal immune system. Nat Rev Immunol. 2014;14(10):667-85.

63. Roxstrom-Lindquist K, Ringqvist E, Palm D, Svard S. Giardia lamblia-induced changes in gene expression in differentiated Caco-2 human intestinal epithelial cells. Infect Immun. 2005;73(12):8204-8.

64. Lee HY, Hyung S, Lee NY, Yong TS, Han SH, Park SJ. Excretorysecretory products of Giardia lamblia induce interleukin-8 production in human colonic cells via activation of $\mathrm{p} 38$, ERK1/2, NFkappaB and AP-1. Parasite Immunol. 2012;34(4):183-98.
65. Shanware NP, Bray K, Eng CH, Wang F, Follettie M, Myers J, et al. Glutamine deprivation stimulates mTOR-JNK-dependent chemokine secretion. Nat Commun. 2014;5:4900.

66. Eri RD, Adams RJ, Tran TV, Tong H, Das I, Roche DK, et al. An intestinal epithelial defect conferring ER stress results in inflammation involving both innate and adaptive immunity. Mucosal Immunol. 2011;4(3):354-64.

67. Oberhuber G, Kastner N, Stolte M. Giardiasis: a histologic analysis of 567 cases. Scand J Gastroenterol. 1997;32(1):48-51.

68. Oberhuber G, Stolte M. Giardiasis: analysis of histological changes in biopsy specimens of 80 patients. J Clin Pathol. 1990;43(8): 641-3.

69. Kamda JD, Singer SM. Phosphoinositide 3-kinase-dependent inhibition of dendritic cell interleukin-12 production by Giardia lamblia. Infect Immun. 2009;77(2):685-93.

70. Obendorf J, Renner Viveros P, Fehlings M, Klotz C, Aebischer T, Ignatius R. Increased expression of CD25, CD83, and CD86, and secretion of IL-12, IL-23, and IL-10 by human dendritic cells incubated in the presence of Toll-like receptor 2 ligands and Giardia duodenalis. Parasites \& Vectors. 2013;6(1):317.

71. Maloney J, Keselman A, Li E, Singer SM. Macrophages expressing arginase 1 and nitric oxide synthase 2 accumulate in the small intestine during Giardia lamblia infection. Microbes and infection / Institut Pasteur. 2015.

72. Oliphant CJ, Barlow JL, McKenzie AN. Insights into the initiation of type 2 immune responses. Immunology. 2011;134(4):378-85.

73. Pulendran B, Artis D. New paradigms in type 2 immunity. Science. 2012;337(6093):431-5.

74. McKenzie AN, Spits H, Eberl G. Innate lymphoid cells in inflammation and immunity. Immunity. 2014;41(3):366-74.

75. Li E, Zhou P, Petrin Z, Singer SM. Mast cell-dependent control of Giardia lamblia infections in mice. Infect Immun. 2004;72(11): 6642-9.

76. Bienz M, Dai WJ, Welle M, Gottstein B, Muller N. Interleukin-6deficient mice are highly susceptible to Giardia lamblia infection but exhibit normal intestinal immunoglobulin A responses against the parasite. Infect Immun. 2003;71(3):1569-73.

77. Kamda JD, Nash TE, Singer SM. Giardia duodenalis: dendritic cell defects in IL-6 deficient mice contribute to susceptibility to intestinal infection. Exp Parasitol. 2012;130(3):288-91.

78. Zhou P, Li E, Zhu N, Robertson J, Nash T, Singer SM. Role of interleukin-6 in the control of acute and chronic Giardia lamblia infections in mice. Infect Immun. 2003;71(3):1566-8.

79. Matowicka-Karna J, Dymicka-Piekarska V, Kemona H. IFN-gamma, IL-5, IL-6 and IgE in patients infected with Giardia intestinalis. Folia Histochem Cytobiol / Pol Acad Sci ChemPolish Hist Cytochem Soc. 2009;47(1):93-7.

80. Matowicka-Karna J, Kralisz M, Kemona H. Assessment of the levels of nitric oxide (NO) and cytokines (IL-5, IL-6, IL-13, TNF, IFN-gamma) in giardiosis. Folia Histochem Cytobiol / Pol Acad Sci ChemPolish Hist Cytochem Soc. 2011;49(2):280-4.

81. Bayraktar MR, Mehmet N, Durmaz R. Role of IL-2, IL-4 and IL10 in patients infected with Giardia lamblia. Turkiye parazitolojii dergisi/Turkiye Parazitoloji Dernegi=. Acta Parasitol Turcica / Turkish Soc Parasitol. 2005;29(3):160-2.

82. Bayraktar MR, Mehmet N, Durmaz R. Serum cytokine changes in Turkish children infected with Giardia lamblia with and without allergy: effect of metronidazole treatment. Acta Trop. 2005;95(2): 116-22.

83. Hagel I, Cabrera M, Puccio F, Santaella C, Buvat E, Infante B, et al. Co-infection with Ascaris lumbricoides modulates protective immune responses against Giardia duodenalis in school Venezuelan rural children. Acta Trop. 2011;117(3):189-95.

84. Hagel I, Puccio F, Lopez E, Lugo D, Cabrera M, Di Prisco MC. Intestinal parasitic infections and atopic dermatitis among Venezuelan Warao Amerindian pre-school children. Pediatr 
Allergy Immunol Off Pub Eur Soc Pediat Allergy Immunol. 2014;25(3):276-82.

85. Cotton JA, Bhargava A, Ferraz JG, Yates RM, Beck PL, Buret AG. Giardia duodenalis cathepsin B proteases degrade intestinal epithelial interleukin-8 and attenuate interleukin-8-induced neutrophil chemotaxis. Infect Immun. 2014.

86. Ebert EC. Giardia induces proliferation and interferon gamma production by intestinal lymphocytes. Gut. 1999;44(3):342-6.

87. Long KZ, Rosado JL, Santos J, Haas M, Al Mamun A, DuPont $\mathrm{HL}$, et al. Associations between mucosal innate and adaptive immune responses and resolution of diarrheal pathogen infections. Infect Immun. 2010;78(3):1221-8.

88. Hanevik K, Kristoffersen E, Svard S, Bruserud O, Ringqvist E, Sornes $\mathrm{S}$, et al. Human cellular immune response against Giardia lamblia 5 years after acute giardiasis. J Infect Dis. 2011;204(11): 1779-86. This is one of the very few studies that try to systematically elucidate the immunological mechanism of giardiasis in an outbreak scenario ("Bergen outbreak"). This paper is representatively highlighted for all investigations during and after the "Bergen outbreak" as the work clearly moved our knowledge about human giardiasis a step forward.

89. Istre GR, Dunlop TS, Gaspard GB, Hopkins RS. Waterborne giardiasis at a mountain resort: evidence for acquired immunity. Am J Public Health. 1984;74(6):602-4.

90. Nash TE, Herrington DA, Losonsky GA, Levine MM. Experimental human infections with Giardia lamblia. J Infect Dis. 1987;156(6):974-84.

91. Veenemans J, Mank T, Ottenhof M, Baidjoe A, Mbugi EV, Demir AY, et al. Protection against diarrhea associated with Giardia intestinalis Is lost with multi-nutrient supplementation: a study in Tanzanian children. PLoS Negl Trop Dis. 2011;5(6), e1158.

92. Bartelt LA, Roche J, Kolling G, Bolick D, Noronha F, Naylor C, et al. Persistent $\mathrm{G}$. lamblia impairs growth in a murine malnutrition model. J Clin Invest. 2013;123(6):2672-84. This new mouse model of giardiasis may help to shed new light on the pathophysiological mechanisms during G. duodenalis infections. It is the first model that reliably models symptomatic giardiasis in the mouse.

93. Benere E. T VANA, C VANG, Peulen O, Cos P, Maes L. Intestinal growth and pathology of Giardia duodenalis assemblage subtype AI, AII, B and E in the gerbil model. Parasitology. 2012;1-10.

94. Solaymani-Mohammadi S, Singer SM. Host immunity and pathogen strain contribute to intestinal disaccharidase impairment following gut infection. J Immunol. 2011;187(7):3769-75.

95. Breathnach AS, McHugh TD, Butcher PD. Prevalence and clinical correlations of genetic subtypes of Giardia lamblia in an urban setting. Epidemiol Infect. 2010;138(10):1459-67.

96. Haque R, Roy S, Kabir M, Stroup SE, Mondal D, Houpt ER. Giardia assemblage A infection and diarrhea in Bangladesh. J Infect Dis. 2005;192(12):2171-3.

97. Homan WL, Mank TG. Human giardiasis: genotype linked differences in clinical symptomatology. Int J Parasitol. 2001;31(8):822-6.

98. Read C, Walters J, Robertson ID, Thompson RC. Correlation between genotype of Giardia duodenalis and diarrhoea. Int $\mathrm{J}$ Parasitol. 2002;32(2):229-31.

99. Sahagun J, Clavel A, Goni P, Seral C, Llorente MT, Castillo FJ, et al. Correlation between the presence of symptoms and the Giardia duodenalis genotype. Eur J Clin Microbiol Infect Dis Off Pub Eur Soc Clin Microbiol. 2008;27(1):81-3.

100. Char S, Cevallos AM, Farthing MJ. An immunodominant antigen of Giardia lamblia is a heat shock protein. Biotechnol Ther. 1992;3(3-4):151-7.
101. Das S, Traynor-Kaplan A, Kachintorn U, Aley SB, Gillin FD. GP49, an invariant GPI-anchored antigen of Giardia lamblia. Brazilian journal of medical and biological research=Revista brasileira de pesquisas medicas e biologicas/Sociedade Brasileira de Biofisica [et al.]. 1994;27(2):463-9.

102. Hasan SM, Maachee M, Cordova OM, Diaz de la Guardia R, Martins M, Osuna A. Human secretory immune response to fatty acid-binding protein fraction from Giardia lamblia. Infect Immun. 2002;70(4):2226-9.

103. Janoff EN, Craft JC, Pickering LK, Novotny T, Blaser MJ, Knisley CV, et al. Diagnosis of Giardia lamblia infections by detection of parasite-specific antigens. J Clin Microbiol. 1989;27(3):431-5.

104. Taylor GD, Wenman WM. Human immune response to Giardia lamblia infection. J Infect Dis. 1987;155(1):137-40.

105. Torian BE, Barnes RC, Stephens RS, Stibbs HH. Tubulin and high-molecular-weight polypeptides as Giardia lamblia antigens. Infect Immun. 1984;46(1):152-8.

106. Upcroft JA, Capon AG, Dharmkrong-At A, Healey A, Boreham PF, Upcroft P. Giardia intestinalis antigens expressed in Escherichia coli. Mol Biochem Parasitol. 1987;26(3):267-76.

107. Wenman WM, Meuser RU, Nyugen Q, Kilani RT, el-Shewy K, Sherburne R. Characterization of an immunodominant Giardia lamblia protein antigen related to alpha giardin. Parasitol Res. 1993;79(7):587-92.

108. Palm JE, Weiland ME, Griffiths WJ, Ljungstrom I, Svard SG. Identification of immunoreactive proteins during acute human giardiasis. J Infect Dis. 2003;187(12):1849-59.

109. Ringqvist E, Palm JE, Skarin H, Hehl AB, Weiland M, Davids BJ, et al. Release of metabolic enzymes by Giardia in response to interaction with intestinal epithelial cells. Mol Biochem Parasitol. 2008;159(2):85-91.

110. Stadelmann B, Hanevik K, Andersson MK, Bruserud O, Svard SG. The role of arginine and arginine-metabolizing enzymes during Giardia - host cell interactions in vitro. BMC Microbiol. 2013;13(1):256.

111. Stadelmann B, Merino MC, Persson L, Svard SG. Arginine consumption by the intestinal parasite Giardia intestinalis reduces proliferation of intestinal epithelial cells. PLoS One. 2012;7(9), e45325.

112. Banik S, Renner Viveros P, Seeber F, Klotz C, Ignatius R, Aebischer T. Giardia duodenalis arginine deiminase modulates the phenotype and cytokine secretion of human dendritic cells by depletion of arginine and formation of ammonia. Infect Immun. 2013;81(7):2309-17.

113. Lee HY, Kim J, Noh HJ, Kim HP, Park SJ. Giardia lamblia binding immunoglobulin protein triggers maturation of dendritic cells via activation of TLR4-MyD88-p38 and ERK1/2 MAPKs. Parasite Immunol. 2014;36(12):627-46.

114. DuBois KN, Abodeely M, Sajid M, Engel JC, McKerrow JH. Giardia lamblia cysteine proteases. Parasitol Res. 2006;99(4): 313-6.

115. Rodriguez-Fuentes GB, Cedillo-Rivera R, Fonseca-Linan R, Arguello-Garcia R, Munoz O, Ortega-Pierres G, et al. Giardia duodenalis: analysis of secreted proteases upon trophozoiteepithelial cell interaction in vitro. Mem Inst Oswaldo Cruz. 2006;101(6):693-6.

116. Jimenez JC, Fontaine J, Creusy C, Fleurisse L, Grzych JM, Capron M, et al. Antibody and cytokine responses to Giardia excretory/secretory proteins in Giardia intestinalis-infected BALB/c mice. Parasitol Res. 2014;113(7):2709-18.

117. Badurdeen S, Mulongo M, Berkley JA. Arginine depletion increases susceptibility to serious infections in preterm newborns. Pediatr Res. 2015;77(2):290-7. 